\title{
CASE REPORT: UNUSAL FOREIGN BODY IN SUBMANDIBULAR SPACE
}

Anjana Agrawal, Rashmi Shukla, Gurchand Singh

\author{
1. Associate Professor, Department of E.N.T, R. D. Gardi Medical College, Ujjain (M.P.) \\ 2. Resident, M.S. Department of E.N.T, R .D. Gardi Medical College, Ujjain (M.P. ) \\ 3. Resident, M.S. Department of E.N.T, R .D. Gardi Medical College, Ujjain (M.P.)
}

\section{CORRESPONDING AUTHOR}

Dr. Anjana Agrawal

43, Alkapuri Colony

Kothi - Maksi Link Road

Ujjain - 456010 (MP)

E-mail: drrashmishuklajha@gmail.com,

Ph: 0091 9893138695, 00919630691179,00917509696069

ABSTRACT: A rare case report of submandibular space infection secondary to a vegetative foreign body (stalk of wheat crop ) which penetrated the floor of mouth to reach the submandibular space and resulted in the formation of abscess. The abscess was drained and the stalk of wheat measuring $2.5 \mathrm{cms}$ in length, removed in toto.

KEYWORDS : foreign body, submandibular space, Wharton's duct

INTRODUCTION : Lodgement of a vegetative foreign body in Submandibular space is a rare case. In chronic and advanced inflammatory process due to foreign body in the gland itself or in the Wharton's duct, submandibular gland excision is mandatory. This case is reported as submandibular abscess due to lodgement of a stalk of wheat crop, in the submandibular space penetrating into the submandibular gland.

The pathology was attributed to the entry of the straw of wheat crop into the mouth with subsequent migration of the stalk into the submandibular space through the floor of mouth as a result of masticatory movements.

CASE REPORT: A 40 years old female, farmer by occupation, presented with the complaints of a swelling in the left submandibular region of neck of 15 days duration with pain in the swelling for last 10 days. She gave history of entry of a stalk of wheat crop into the mouth 20 days back while she was cutting the crops. Patient tried to manually remove the stalk with her finger and possibly pushed it deeper, as a result of which the stalk penetrated the floor of mouth and reached the submandibular space. There was no history of increase in the size of swelling during meals.

On local examination, there was a firm, tender, immobile swelling of size $5 \mathrm{X} 4 \mathrm{cms}$ in the left submandibular region. The swelling had smooth surface, diffuse margins, raised temperature.

On examination of oral cavity, there was slight edema and congestion in floor of mouth. No ulcer or entry point seen.

Other relevant ENT examination was normal.

FNAC of the swelling was suggestive of an abscess.

The Ultrasonography report showed a hyperechoic foreign body in the left submandibular space penetrating the submandibular gland which was surrounded by oedema and abscess.

Journal of Evolution of Medical and Dental Sciences/Volume1/Issue5/November-2012Page-697 
Patient was started on intravenous antibiotics and anti inflammatory drugs. The swelling subsided in 4 days.

Then the patient was planned for surgical removal of the foreign body under general anaesthesia. A fragment of vegetable crop of length about $2.5 \mathrm{cms}$ was found embedded within the submandibular space penetrating the submandibular gland surrounded by abscess.

The abscess was drained and the foreign body was removed.

Post-operative antibiotics and anti inflammatory drugs were given for 7 days. Postoperative period was uneventful and patient was discharged on $7^{\text {th }}$ day.

\section{DISCUSSION:}

Submandibular space

- The submandibular space is bounded above by mucous membrane of the floor of mouth and tongue and below by the deep cervical fascia that extends from the hyoid to the mandible. It is divided into two by the mylohyoid muscles. The space superior to mylohyoid is called the sublingual space and contains the sublingual gland, the space inferior to muscle is the submaxillary space and contains the submandibular gland.

- Sublingual space communicates with the submaxillary space through the posterior margin of the mylohyoid muscle, around which pus can easily travel.

- Common causes of infection in the submandibular space are oral trauma, dental abscess of mandibular teeth, submandibular or sublingual sialadenitis. Odontogenic infection in adults is the most common cause among these, and foreign bodies being one of the rarest.[1-3] Prior to this, only a single case of deep neck space infection secondary to foreign body in submandibular space has been reported in literature. ${ }^{[3]}$ The passage of the foreign body, in this location, can cause local pain. So, surgical removal of the foreign body of the submandibular space is the treatment left because the spontaneous expulsion is not possible due to its anatomy. For proper removal of foreign body, preoperative localization is very important. CT scan is unreliable in detecting unpainted wooden foreign bodies. ${ }^{[4]}$ In our case, USG proved very useful.

- In the case of foreign body which cannot be accurately localised or is situated posterioly, a traditional submandibular approach through horizontal cervical skin incision is a preferable choice as it is simple and safe method for removal of foreign body and complications can be prevented.[5] In our case there was no complication, except painful swelling of the neck and trismus.

Initial care of patients with a submandibular abscess includes broad spectrum intravenous antibiotics to cover for both aerobic and anaerobic organisms. Other treatment modalities for submandibular abscess include needle aspiration and drainage. Open surgical drainage is mandatory in the cases of abscess formation with suspected foreign body.

\section{REFERENCES:}

1) Maran AG, Mackenzie IJ, Murray JA. The parapharyngeal space. J Laryngol Otol 1984; 98:371-380. 6325567

2) Abemayor E, Lufkin R. Enhancing accesss to the parapharyngeal space. Laryngoscope 2002; 112:757-759. 12150536 
3) Coales UF, Tandon P, Hinton AF. Limitations of imaging for foreign bodies in parapharyngeal abscess and the importance of surgical exploration. J Laryngol Otol 1999; 113:683-685. 10605573

4) Limitations of imaging for foreign bodies in parapharyngeal abscess and the importance of surgical exploration. J Laryngol Otol 1999; 113:683-685. 10605573

5) Kalsotra PK, Thakar A, Kumar R. Foreign body in the Wharton's duct. Ind J Otolaryngol Head Neck Surg, 1995; 47(4): 297-98.

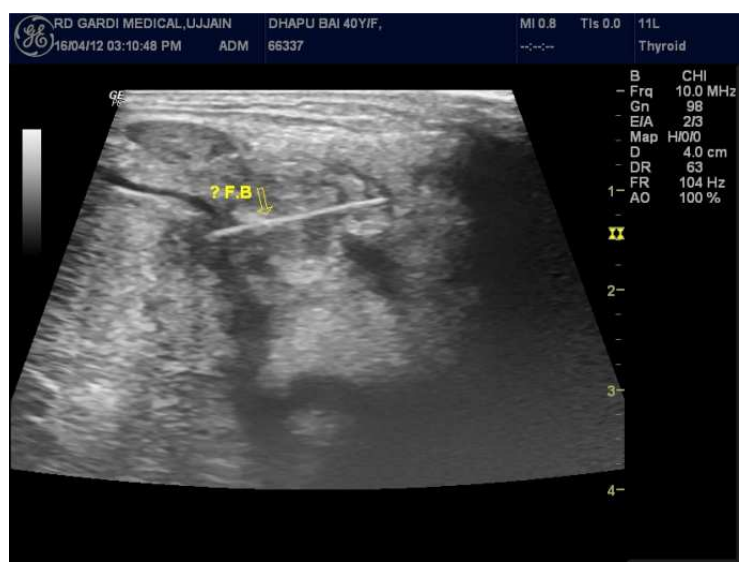

Figure 1 : USG showing FB in submandibular space penetrating the gland

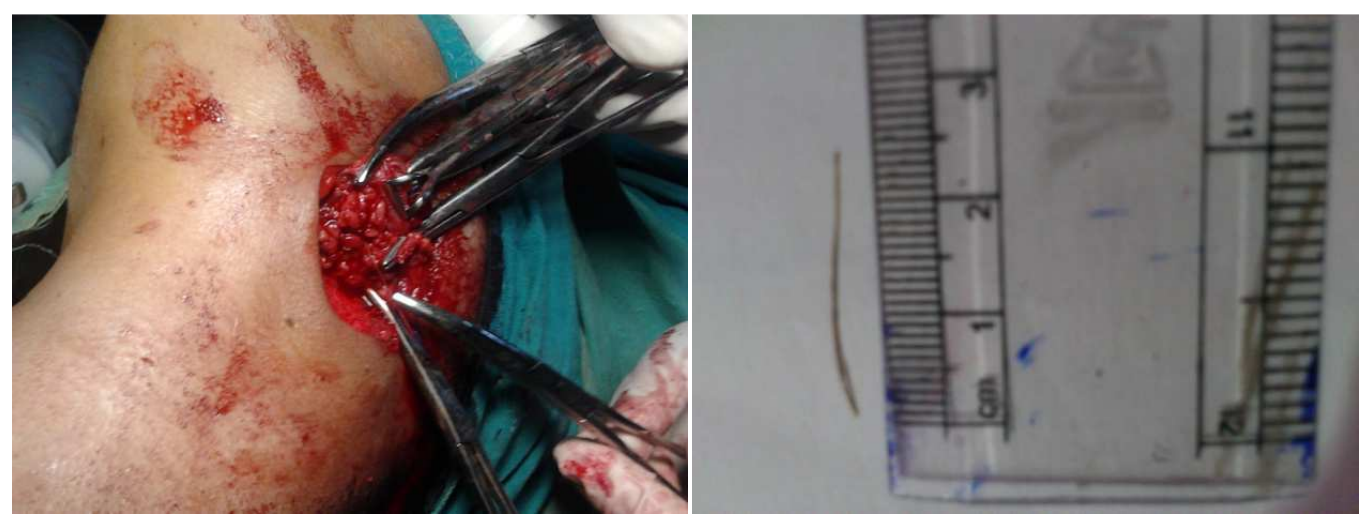

Figure 2 : showing F.B. wheat stalk in

Figure 3 : showing wheat stalk removed from the left left submandibular space 